\title{
COBERTURAS CENOZÓICAS E ESTRUTURAS DEFORMADORAS NA DEPRESSÃO PERIFÉRICA PAULISTA, CAMPINAS, SÃO PAULO
}

Amélia João FERNANDES

Claudio Limeira MELLO

\begin{abstract}
RESUMO
Este trabalho teve como objetivo mapear e estabelecer a estratigrafia dos depósitos cenozóicos e caracterizar as estruturas tectônicas deformadoras em um setor da Região Metropolitana de Campinas, no contato da Depressão Periférica Paulista com o Planalto Atlântico. Na região de estudo foram identificadas três unidades cenozóicas, associadas a depósitos de topo e encosta de colinas, que correspondem, da mais antiga à mais jovem, à Formação Rio Claro (Trc) e às coberturas de superfícies aplainadas (TQsp) e de fluxos gravitacionais (Qfg). A Trc é constituída por fácies de ambiente fluvial meandrante intercaladas, ou em contato lateral, com fácies de fluxos gravitacionais. A TQsp ocorre nos topos de colinas e morrotes e nas ombreiras planas de caimento suave; é constituída por material areno-argiloso a arenoso, com linha de seixos na base. A Qfg é de ocorrência restrita e associa-se a encostas de vales atuais, espessando-se em direção à sua base; são depósitos coluviais, ocasionalmente intercalados com depósitos de terraços fluviais. Os depósitos Qfg apresentam linha de seixos basal composta por clastos ferruginizados, que se originaram das couraças ferruginosas desenvolvidas sobre os depósitos da Trc. Na área foram identificadas estruturas de três eventos tectônicos cenozóicos. O mais antigo é de regime transcorrente com $\sigma 1$ de orientação aproximadamente EW, provavelmente contemporâneo à deposição da Trc; originou falhas transcorrentes de direção NE e NW e falhas normais de direção ao redor de EW. O evento seguinte, com $\sigma 1$ de direção NW, produziu falhas EW a WNW e NS a NNW transcorrentes, com componente normal. Este evento afeta a Trc e a TQsp e produziu desnivelamentos tectônicos da superfície basal da Trc que, somados, chegam a pelo menos $50 \mathrm{~m}$. O evento mais jovem é de regime extensional, com $\sigma 3$ de direção NE, e gerou falhas normais que cortam a Trc e a TQsp.
\end{abstract}

Palavras-chave: Formação Rio Claro, depósitos cenozóicos, tectônica cenozóica, Campinas-SP.

\section{ABSTRACT}

The study area is located in the Metropolitan Region of Campinas, on the contact between the Depressão Periférica Paulista and the Atlantic Plateau. The work here presented aims at mapping the Cenozoic deposits and also the tectonic structures that deform them. Three Cenozoic deposit units, associated to hill tops and slopes, were identified; from the oldest to the youngest, they correspond to: Rio Claro Formation (Trc), planation surface deposits (TQsp), and gravitational flow deposits (Qfg). The Trc deposits consist of meandering fluvial facies intercalated, or in lateral contact, with gravitational flow facies. The TQsp occurs at the top or on gently sloping divides of gentle and rolling hills. It consists of sandy-clayey or sandy deposits underlain by a stone line. The Qfg occurrences are very restrict, associated to the lower portion of slopes, and its thickness increases towards current valleys; it consists of both colluvial, with a basal stone line, and fluvial terrace 
deposits. This stone line sometimes contains ferruginous fragments originated from ferricretes of the Trc sediments. Two older strike-slip Cenozoic events and a younger extensional one affect the Cenozoic deposits. The older, with $\sigma 1$ trending around EW, has generated strike-slip NE and NW faults, and normal EW ones. It was probably contemporaneous with the deposition of the Trc. The second event, whose $\sigma 1$ trends around NW, has generated EW to WNW and NS to NNW faults, and is probably of transtensional nature. This event affects the Trc and TQsp deposits and has produced vertical tectonic offsets of the basal surface of the Trc totalizing at least $50 \mathrm{~m}$. The younger event, with a sub-horizontal $\sigma 3$ trending around NE, has generated NE normal faults, which affect the Trc and TQsp sediments.

Keywords: Rio Claro Formation, Cenozoic deposits, Cenozoic tectonics, Campinas-SP.

\section{INTRODUÇÃO}

A área de estudo insere-se na Região Metropolitana de Campinas (RMC), no contato da Depressão Periférica Paulista com o Planalto Atlântico, onde afloram rochas da Bacia do Paraná e précambrianas, respectivamente (Figura 1). Ela pertence à $5^{\text {a }}$ Unidade de Gerenciamento de Recursos Hídricos (UGRHI-5), a qual é composta pelas bacias hidrográficas dos rios Piracicaba, Capivari e Jundiaí.

O presente trabalho sintetiza as descrições de FERNANDES (1997) e INSTITUTO GEOLÓGICO (2002) e apresenta novos dados e interpretações relativos às unidades de cobertura e à deformação rúptil cenozóica presentes na região de Campinas.

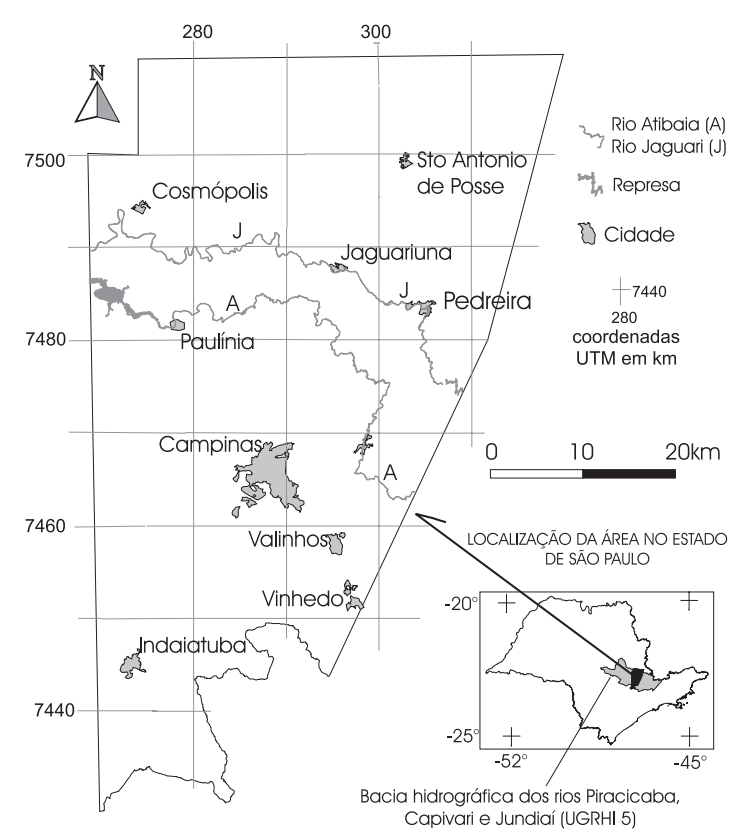

FIGURA 1 - Mapa de localização da área de estudo.
Os trabalhos mencionados basearam-se em trabalhos de campo, interpretação de fotografias aéreas, coleta e análise de dados de estruturas tectônicas, com ênfase nas cenozóicas, e, também, em duas datações ${ }^{14} \mathrm{C}$ de carvões contidos em uma das unidades cenozóicas identificadas.

O projeto desenvolvido pelo INSTITUTO GEOLÓGICO (2002), denominado “Mapeamento da vulnerabilidade natural dos aqüíferos fraturados précambrianos da RMC”, que complementou o mapeamento das coberturas cenozóicas na RMC, considerou que as características texturais e de espessura das coberturas sedimentares superficiais têm influência significativa sobre a vulnerabilidade dos aquiíferos fraturados, constituídos, na região, por gnaisses e granitos, pois representam os estratos mais superficiais da zona não-saturada. Esta, em função de sua constituição, pode oferecer maior ou menor capacidade de atenuação dos contaminantes gerados por atividades humanas.

\section{CONHECIMENTOS PRÉVIOS}

2.1. O embasamento das coberturas na área de estudo

A região foi alvo de vários mapeamentos, principalmente em escala 1:50.000, tais como os de BASEI et al. (1986), PELLOGIA (1990), INSTITUTO GEOLÓGICO (1993, 1995, 2002), VLACH (1993) e FERNANDES (1997). O embasamento das coberturas cenozóicas, na porção oriental da região de Campinas, é constituído por gnaisses e granitos précambrianos e, na porção ocidental, pelo Grupo Itararé (Permo-Carbonífero) e diabásios (Cretáceo) (Figura 2).

Os gnaisses ocorrem em dois grandes domínios que correspondem à Nappe de Empurrão Socorro-Guaxupé (NESG) (Mesoproterozóico), e à Faixa 
Alto Rio Grande (FARG) (Arqueano/Eoproterozóico e Mesoproterozóico) (CAMPOS NETO et al. 1984, CAMPOS NETO 1990).

Os gnaisses apresentam foliação principal de direção NE, variando para NNE e NS, e mais restritamente EW (a norte da área urbana de Campinas) e NW (a leste de Souzas) (INSTITUTO GEOLÓGICO 1993,1995, 2002; FERNANDES 1997). Estas rochas são intrudidas pelos granitos Jaguariúna, Morungaba, Itu e alguns corpos menores indiferenciados, todos do final do Neoproterozóico.

O Grupo Itararé recobre as rochas précambrianas na porção ocidental da região de Campinas e é constituído por arenitos, diamictitos, ritmitos, argilitos e conglomerados descritos detalhadamente em INSTITUTO GEOLÓGICO (1993, 1995) e FERNANDES (1997).

Os diabásios intrudem as rochas précambrianas e o Grupo Itararé, comportando-se em parte como diques e em parte como soleiras, e foram originados pelo mesmo evento magmático da Formação Serra Geral. Apresentam granulação fina a média e estrutura maciça e são mais abundantes e contínuos entre Paulínia e Campinas e a oeste de Santo Antônio de Posse.

\subsection{Geomorfologia e coberturas cenozóicas}

A área de estudo está contida na Depressão Periférica Paulista que, de acordo com PIRES NETO

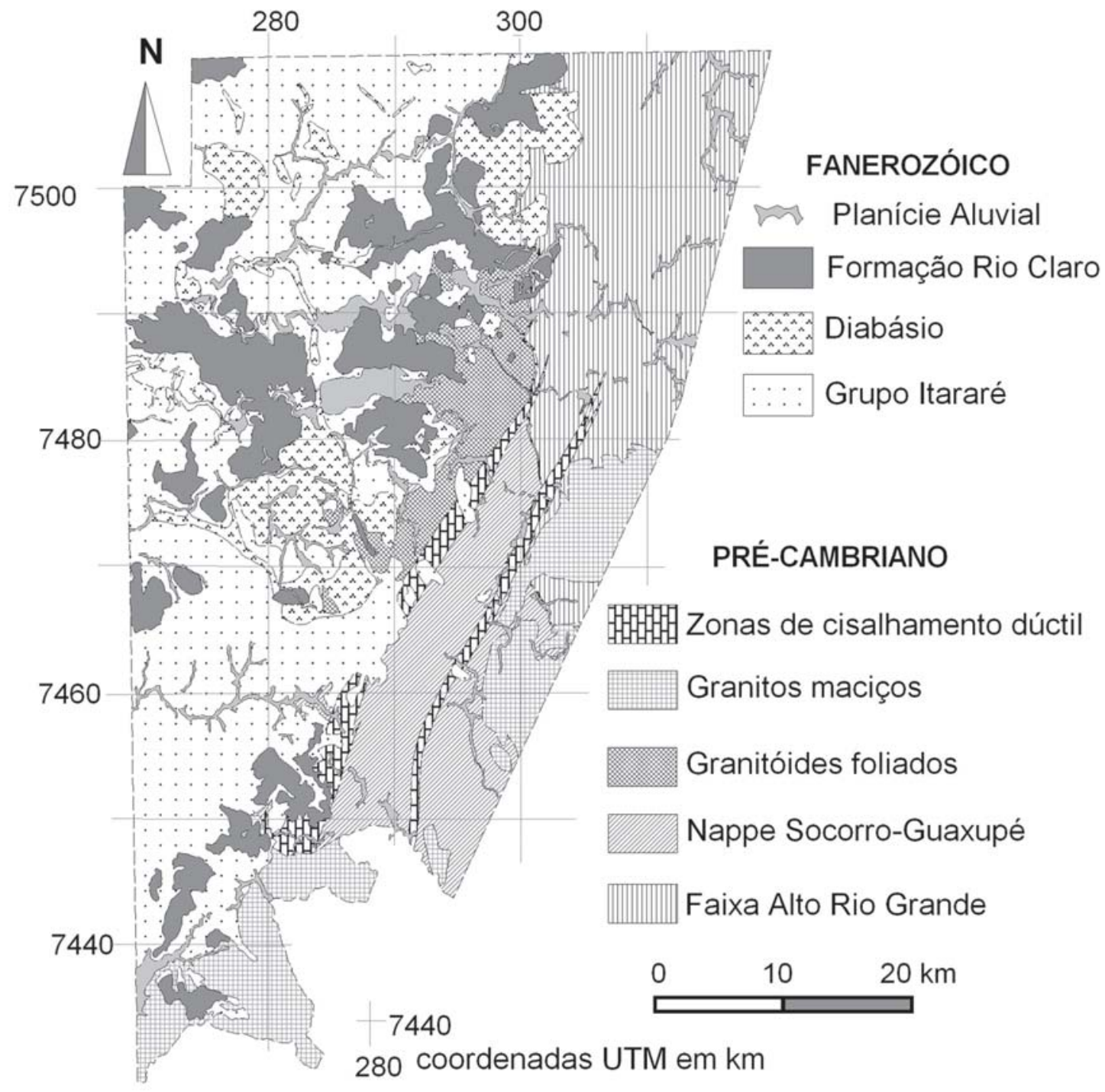

FIGURA 2 - Mapa geológico da área de estudo (Fonte: FERNANDES 1997 e INSTITUTO GEOLÓGICO 2002). 
(1996), contém três zonas geomorfológicas nomeadas de acordo com o nível de preservação da Superfície Neogênica de DE MARTONNE (1943). Estas zonas correspondem a: (1) "zona de relevos remanescentes”, composta por colinas amplas e médias; (2) "zona de dissecação", composta por colinas pequenas e médias; e (3) “zona de contato” com a Serrania de Lindóia, do Planalto Atlântico, localizado a leste, composta principalmente por morrotes.

Na Serrania de Lindóia e na zona de contato adjacente, afloram rochas pré-cambrianas pertencentes à NESG e à FARG, além de granitos do final do Neoproterozóico. Nas zonas de relevos remanescentes e de dissecação ocorrem o Grupo Itararé e os diabásios.

A Formação Rio Claro, definidapor BJÖRNBERG \& LANDIM (1966), representa a cobertura cenozóica mais antiga da área de estudo, ocorrendo mais amplamente na zona de relevos remanescentes da Superfície Neogênica e, subordinadamente, nas zonas de contato e de dissecação (FERNANDES 1997). A altitude das suas ocorrências varia de 600 a 800m, constituindo-se predominantemente por arenitos, e apresentando espessura máxima de cerca de 30 m. É marcada na base pela presença de uma cascalheira (FÚLFARO \& SUGUIO1968).

Sedimentos neocenozóicos foram mapeados por CARVALHO et al. (1967), CHRISTOFOLETTI (1968) e NAKASHIMA (1973) na região do aeroporto de Viracopos. CAVALCANTE et al. (1979) mapearam ocorrências isoladas, consideradas pelos autores como correlatas à Formação Rio Claro, a norte de Campinas.

MELO et al. (1997) descreveram quatro fácies na Formação Rio Claro: lamitos de processos gravitacionais, cascalhos e areias de canais e barras fluviais, areias finas de rompimento de diques marginais, e finos de transbordamento em planície de inundação. Segundo estes autores, esta formação estaria situada em dois níveis planálticos, ambos neogênicos, correspondendo a altitudes, em geral, de 610 a $820 \mathrm{~m}$ e 520 a $680 \mathrm{~m}$.

UNESP (1986) e NEVES (1999) descreveram depósitos terciários constituídos por diamictitos, conglomerados, arenitos e argilitos, correspondentes a um antigo sistema de leques aluviais com área fonte na Serra do Japi, localizada a sul dessas ocorrências. A leste, na região de Atibaia-Bragança Paulista, BISTRICHI (2001) mapeou duas seqüências estratigráficas do Terciário, ambas com predomínio de conglomerados, diamictitos e arenitos, as quais representariam depósitos de leques aluviais e lacustres restritos.
Depósitos de natureza colúvio-eluvial recobrem desde as rochas pré-cambrianas até os depósitos terciários (MELO et al. 1997, NEVES 1999) não sendo vinculados a um determinado nível planáltico (MELO et al. 1997). Sedimentos terciários a quaternários de terraços elevados (TQt) aparecem vinculados às formas de vale atuais (MELO et al. 1997).

\subsection{Contexto tectônico}

As principais descontinuidades précambrianas presentes na região correspondem: às zonas de cisalhamento de empurrão que colocam a Faixa Alto Rio Grande em contato com a Nappe Socorro-Guaxupé (BASEI et al. 1986, CAMPOS NETO et al. 1984, VASCONCELLOS 1988, CAMPOS NETO 1990) e às zonas de cisalhamento transcorrentes de Valinhos e Campinas, de direção NNE, ativas desde o final do Neoproterozóico até o início do Paleozóico (CAVALCANTE et al. 1979, HASUI et al. 1981).

Durante o Paleozóico, descontinuidades de direção NW e NE controlaram a sedimentação da Bacia do Paraná(VIEIRA 1973, FERREIRA et al. 1981, SOARES et al. 1982, FÚLFARO et al. 1982, CORDANI et al. 1984, ZALÁN et al.1991).

A tectônica mesozóica e a evolução sedimentar na Bacia do Paraná foram fortemente afetadas pela ruptura do Gondwana e a abertura do Atlântico Sul, e não mais pelos eventos da orogenia Andina, como teria ocorrido durante o Paleozóico. Até o Jurássico, a Bacia do Paraná passou por período de intumescência e, no Eocretáceo, houve um volumoso extravasamento de lavas (ZALÁN et al. 1991). No Triássico e Eocretáceo teria se desenvolvido o terceiro trend estrutural mais importante da Bacia do Paraná, que corresponderia à direção EW (MACEDO 1990, ZALÁN et al. 1991).

Na região de Campinas falhas de direções predominantes N30-60E e EW a WNW, com rejeitos no mínimo métricos, normais, e mergulhos elevados a médios, colocam as rochas gnáissicas em contato lateral com o Grupo Itararé. Elas seriam sincrônicas à tectônica extensional que foi contemporânea à colocação dos corpos de diabásio do Eocretáceo (FERNANDES 1997, FERNANDES \& AMARAL 2002), e cuja direção do esforço mínimo principal ( $\sigma 3$ ) pode ter variado ao longo do tempo, permitindo a geração de falhas normais de direção distinta. Isto é compatível com a variação das direções de diques de diabásio contemporâneos ao magmatismo Serra Geral, que no Arco de Ponta Grossa são predo- 
minantemente NW e, secundariamente, NE e EW (PORTELA FILHO 2003), e no litoral norte do Estado de São Paulo, principalmente de direção NE (GARDA 1995).

Vários estudos descreveram atividade tectônica importante de idade cenozóica dentro do Estado de São Paulo, podendo ser citados entre outros: BJÖRNBERG (1965), BJÖRNBERG et al. (1971), CAMPANHA et al. (1985), RICCOMINI et al. (1989), MELO (1990), MELO et al. (1993), SALVADOR \& RICCOMINI (1995), HASUI et al. (1995), MELO et al. (1997), RICCOMINI (1997), FERNANDES da SILVA (1998), NEVES (1999), HIRUMA et al. (2001). Os resultados de parte destes estudos são sintetizados na tabela 1 .

FERNANDES (1997) e FERNANDES \& AMARAL (2002) identificaram, na área de estudo, cinco eventos tectônicos de regime transcorrente, posteriores ao magmatismo Serra Geral, denominados, do mais antigo para o mais recente, E1-NE, E2-EW, E3-NW, E4-NS, E5-NNE. Com exceção do mais antigo, todos afetam a Formação Rio Claro. Depósitos atribuídos ao Quaternário e que se sobrepõem à Formação Rio
Claro são afetados pelos três últimos eventos (FERNANDES 1997, FERNANDES \& AMARAL 2002). As principais estruturas por eles geradas correspondem a falhas transcorrentes, muitas vezes com componentes oblíquas, e fraturas conjugadas, ambas de mergulhos elevados a subverticais. Falhas normais ou inversas são de ocorrência subordinada. A tabela 2 apresenta, esquematicamente, a orientação dos esforços para cada um destes eventos.

Segundo FERNANDES (1997) e FERNANDES \& AMARAL (2002), a região apresenta quatro trends de lineamentos bem definidos, que correspondem a: (1) N75-90W a N80-90E; (2) N30-55W, com máximo ao redor de N40-50W, para as rochas pré-cambrianas, e N35-50W, para a Bacia do Paraná ; (3) N20-40E; e (4) NS a N10E para as rochas pré-cambrianas e, secundariamente, NS a N5W, para a Bacia do Paraná. Todas as direções passam continuamente dos terrenos précambrianos para a Bacia do Paraná e existe uma correspondência bastante forte entre estes trends e as direções das fraturas identificadas nos afloramentos (FERNANDES 1997, FERNANDES \& AMARAL 2002).

Tabela 1. Eventos tectônicos mesozóico-cenozóicos no Estado de São Paulo, segundo diferentes autores. $\sigma 1=$ esforço máximo principal, $\sigma 3=$ esforço mínimo principal.

\begin{tabular}{|c|c|c|c|c|c|c|c|c|c|}
\hline & \multicolumn{9}{|c|}{ IDADE E DESCRIÇÃO DO CAMPO DE ESFORÇOS E DA DEFORMAÇÃO } \\
\hline Autor e área estudada & K SUPERIOR & PALEÓGENO & NEÓGENO & & PLEISTOCENO & \multicolumn{4}{|c|}{ HOLOCENO } \\
\hline $\begin{array}{l}\text { Riccomini et al. (1989) } \\
\text { Rift Ccontinental do } \\
\text { Sudeste do Brasil }\end{array}$ & & $\begin{array}{l}\text { extensão NNW- } \\
\text { SSE } \\
\text { sincrônica à } \\
\text { sedimentação }\end{array}$ & $\begin{array}{l}\text { compressão NE-SW } \\
\text { binário EW sinistral }\end{array}$ & & $\begin{array}{l}\text { NW-SE, binário EW } \\
\text { tral }\end{array}$ & Exten & ensão, com $\sigma 3$ de & direçãc & NW-SE \\
\hline $\begin{array}{l}\text { Salvador \& Riccomini } \\
\text { (1995), Alto estrutural de } \\
\text { Queluz } \\
\text { Mancini (1995) Bacia de } \\
\text { Taubaté }\end{array}$ & & $\begin{array}{l}\text { extensão NNW- } \\
\text { SSE, } \\
\text { gerou estruturas } \\
\text { ENE e WNW }\end{array}$ & $\begin{array}{l}\text { compressão NE-SW } \\
\text { binário sinistral EW }\end{array}$ & & $\begin{array}{l}\text { compressão } \\
\text { NW-SE, binário EW } \\
\text { dextral }\end{array}$ & & $\begin{array}{l}\text { xtensão WNW- } \\
\text { SE, grabens NS }\end{array}$ & compr & essão EW atual \\
\hline $\begin{array}{l}\text { Hasui et al. (1995) } \\
\text { Região de São Pedro, } \\
\text { Neves (1999) } \\
\text { Região de Jundiaí }\end{array}$ & $\begin{array}{l}\text { Regime distens } \\
\text { direção NW-SE } \\
\text { de direção NE- }\end{array}$ & $\begin{array}{l}\text { ivo com } \sigma 3 \text { de } \\
\text { e falhas normais } \\
\text { SW }\end{array}$ & Regime transcorrente & om com & o1 de direção NW-SE e & $\sigma 3 \mathrm{~d}$ & de direção NE-SW & & \\
\hline $\begin{array}{l}\text { Riccomini (1997) } \\
\text { Bacia Bauru }\end{array}$ & Regime transc & rrente com $\sigma 1$ de $d$ & lireção EW. & & $\begin{array}{l}\text { Regime transcorrente } \\
\text { Falhas transcorrentes }\end{array}$ & $\begin{array}{l}\text { com c } \\
\text { e norr }\end{array}$ & $\begin{array}{l}\sigma 1 \text { de direção NS } \\
\text { rmais. }\end{array}$ & & \\
\hline $\begin{array}{l}\text { Hiruma et al. (2001) } \\
\text { Planalto de Campos do } \\
\text { Jordão }\end{array}$ & & & & & $\begin{array}{l}\text { Regime transcorrente } \\
\sigma 1 \text { de direção NW }\end{array}$ & com & $\begin{array}{l}\text { Distensão EW a } \\
\text { SE }\end{array}$ & NW- & $\begin{array}{l}\text { Regime } \\
\text { transcorrente com } \\
\text { o1 de direção NW- } \\
\text { SE a EW }\end{array}$ \\
\hline $\begin{array}{l}\text { Fernandes (1997), } \\
\text { Fernandes \& Amaral } \\
(2002) \\
\text { Região de Campinas }\end{array}$ & $\begin{array}{l}\text { Regime transc } \\
\text { direção NE. F } \\
\text { EW/ENE sinist } \\
\text { dextrais }\end{array}$ & $\begin{array}{l}\text { rrente com } \sigma 1 \text { de } \\
\text { Ihas tanscorrentes } \\
\text { ais e NS/NNE }\end{array}$ & $\begin{array}{l}\text { Regime transcorrente } \\
\sigma 1 \text { de direção EW. } \\
\text { Falhas transcorrentes } \\
\text { direções NE e NW e fa } \\
\text { normais de direção EV }\end{array}$ & & $\begin{array}{l}\text { Regime transcorrente } \\
\text { com } \sigma 1 \text { de direção NW } \\
\text { Falhas transcorrentes } \\
\text { EW/WNW e NS/NNW } \\
\text { falhas normais NW }\end{array}$ & $\begin{array}{l}\text { Re } \\
\text { N. } \\
\text { tra } \\
\\
\end{array}$ & $\begin{array}{l}\text { egime } \\
\text { anscorrente com de direção NS }\end{array}$ & $\begin{array}{l}\text { Regi } \\
\text { com }\end{array}$ & $\begin{array}{l}\text { ime transcorrente } \\
\sigma 1 \text { de direção NNE }\end{array}$ \\
\hline
\end{tabular}


TABELA 2 - Síntese das estruturas geradas nos eventos tectônicos cenozóicos que afetaram a região, segundo FERNANDES (1997) e FERNANDES \& AMARAL (2002). Todos os eventos foram gerados em regime transcorrente, sendo que o evento E1-NE é anterior à deposição da Formação Rio Claro. Os eventos E2-EW e E3-NW, com falhas transcorrentes de direção N45-65W e N45-65E, para o primeiro, e EW-N70W e NS-N15W, para o segundo, apresentam componente extensional importante, a qual é responsável por deslocamentos verticais e normais. O E2-EW foi contemporâneo à deposição da Formação Rio Claro.

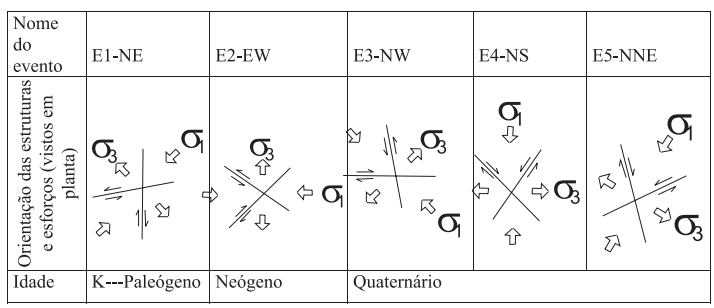

\section{AS COBERTURAS CENOZÓICAS}

O presente trabalho sintetiza as descrições de FERNANDES (1997) e INSTITUTO GEOLÓGICO (2002) e apresenta novos dados e interpretações relativos às unidades de coberturas e à deformação rúptil cenozóica presentes na região de Campinas. Com relação às coberturas, foram descritos os depósitos cenozóicos que ocorrem em posição de topo e encosta de morros e colinas, os quais correspondem às seguintes unidades: (1) Formação Rio Claro (Trc), (2) cobertura associada a superfícies aplainadas (TQsp), e (3) depósitos coluviais associados a rampas suaves, ocasionalmente intercalados com depósitos de terraços, no interior de vales atuais importantes (Qfg). A estratigrafia aqui proposta para estes depósitos baseia-se: (1) na observação de contatos entre as unidades, onde se observa a Trc sendo sobreposta, em contato erosivo e, por vezes, discordante, pela TQsp e Qfg; (2) na associação das coberturas com a morfologia, observando-se que a TQsp ocorre em topos e ombreiras planos ou de caimento suave de colinas e morros, e a Qfg, no terço final de encostas situadas no interior de vales importantes. Em função da escala dos mapeamentos realizados em FERNANDES (1997) e INSTITUTO GEOLÓGICO (2002) (1:50.000 e 1:100.000), dentre as coberturas cenozóicas, somente a Formação Rio Claro é representável em mapa, como observado na figura 2. As demais coberturas são descontínuas e de pequena es- pessura, ou de ocorrência apenas pontual. Os depósitos de terraços fluviais que ocorrem nas planícies aluviais da área não são tratados no presente trabalho, no entanto, a descrição de parte dos mesmos pode ser encontrada em INSTITUTO GEOLÓGICO(1995).

\subsection{Formação Rio Claro (Trc)}

\subsubsection{Fácies e ambientes}

Como anteriormente descrito por FERNANDES (1997), a Formação Rio Claro (Trc) contém, na área estudada, as seguintes fácies:

Si - siltitos a arenitos muito finos com laminação horizontal. A sua cor varia de amarelo ocre a vermelho claro e a espessura, de decimétrica a alguns metros, ocasionalmente chega a 10 a $15 \mathrm{~m}$. Pode conter camadas decimétricas de siltitos ricos em restos de vegetais. Estes fósseis, em variável grau de fragmentação, atingem dimensões centimétricas, podendo ser atribuídos, com dúvidas, às famílias Cyperaceae ou Typhaceae. Tais famílias, com representantes predominantemente paludículas ou lacustres, são muito comuns nas regiões tropicais e temperadas de todo o mundo. Provavelmente estes vegetais se desenvolveram em meandros abandonados, em condições de águas mais calmas, tendo se depositado sob a forma de fragmentos por ocasião das inundações (Fernandes et al. 1994).

Ar - Arenitos quartzosos, grossos ou médios a finos, às vezes conglomeráticos ( $\mathrm{Arc}$ ), mal ou moderadamente selecionados, com grânulos e seixos de quartzo subangulosos ou subarredondados. Apresentam estratificação cruzada planar de médio porte, por vezes acanalada ou cruzada de baixo ângulo, e granodecrescência normal ou inversa. Podem conter camadas centi- a decimétricas de conglomerados e camadas centimétricas da fácies Si. As camadas são lenticulares, por vezes com grande persistência lateral, com comprimento de dezenas de metros e espessuras de, no máximo, 4m (em média de $2 \mathrm{~m}$ ) intercalando-se, em geral, com a fácies Si. Mais raramente, ocorrem corpos de arenitos, de formatos sigmóides, de espessura ao redor de $1 \mathrm{~m}$ e comprimento de alguns metros, intercaladas com a fácies Si. 
C - Conglomerados sustentados por matriz de areia grossa com seixos de quartzo, em camadas de até $1 \mathrm{~m}$ de espessura, intercalam-se com os arenitos $(A r)$.

Ag - Argilitos siltosos, esbranquiçados, com laminação incipiente, formando corpos tabulares extensos com até $2 \mathrm{~m}$ de espessura. Ocasionalmente, são explorados economicamente.

La - Lamitos a arenitos pelíticos, maciços, com esparsos grânulos e seixos de quartzo subarredondados ou subangulosos, cinzentos e com manchas vermelhas. Localmente são argilosos (Laf). Podem ocorrer na base, ao lado ou no topo das demais fácies. Correspondem a vários fluxos de detritos ou corridas de lama, ao todo com vários metros de espessura.

As fácies Si e $\mathrm{Ag}$ representam depósitos de planícies de inundação, com formação de lagos em meandros abandonados, onde se desenvolveram plantas aquáticas, dentro de ambiente fluvial meandrante. A fácies Ar corresponde a depósitos de canais do tipo barra de pontal (areias) e a $C$, a fundo de canal. O formato sigmoidal de alguns corpos de arenitos, em meio à fácies $S i$, sugere que localmente tenham ocorrido processos de rompimento de di- ques marginais e deposição dos arenitos em lagos (possivelmente oxbows) por ocasião das inundações. A fácies $L a$ foi formada por processos gravitacionais (corridas de lama e fluxos de detritos). A associação das fácies pode ser visualizada na Figura 3.

Em função de seu aspecto morfológico, ou seja, topos sub-horizontais de colinas amplas, algumas áreas foram mapeadas, por fotointerpretação, como pertencentes à Formação Rio Claro. Nestas porções, onde a Trc é de constituição indefinida (Figura 4), as exposições em afloramentos não estavam presentes ou foram insuficientes para caracterizar as suas fácies.

A descrição da Trc concorda com a feita por MELO et al. (1997) na Depressão Periférica, os quais concluiram que ela teria se depositado em ambiente fluvial meandrante. Os depósitos terciários da região de Jundiaí, descritos por UNESP (1986) e NEVES (1999) e a seqüência do Mioceno Superior de BISTRICHI (2001) são consideradas correlacionáveis à Trc, pois: (1) assemelham-se em constituição à associação faciológica encontrada nas proximidades de Jaguariúna, onde a Trc, assentada diretamente sobre as rochas pré-cambrianas, é constituída predominantemente por lamitos maciços com seixos e grânulos (depósitos de fluxos de detritos), contendo ocasionalmente finas lentes de argilitos-siltitos e
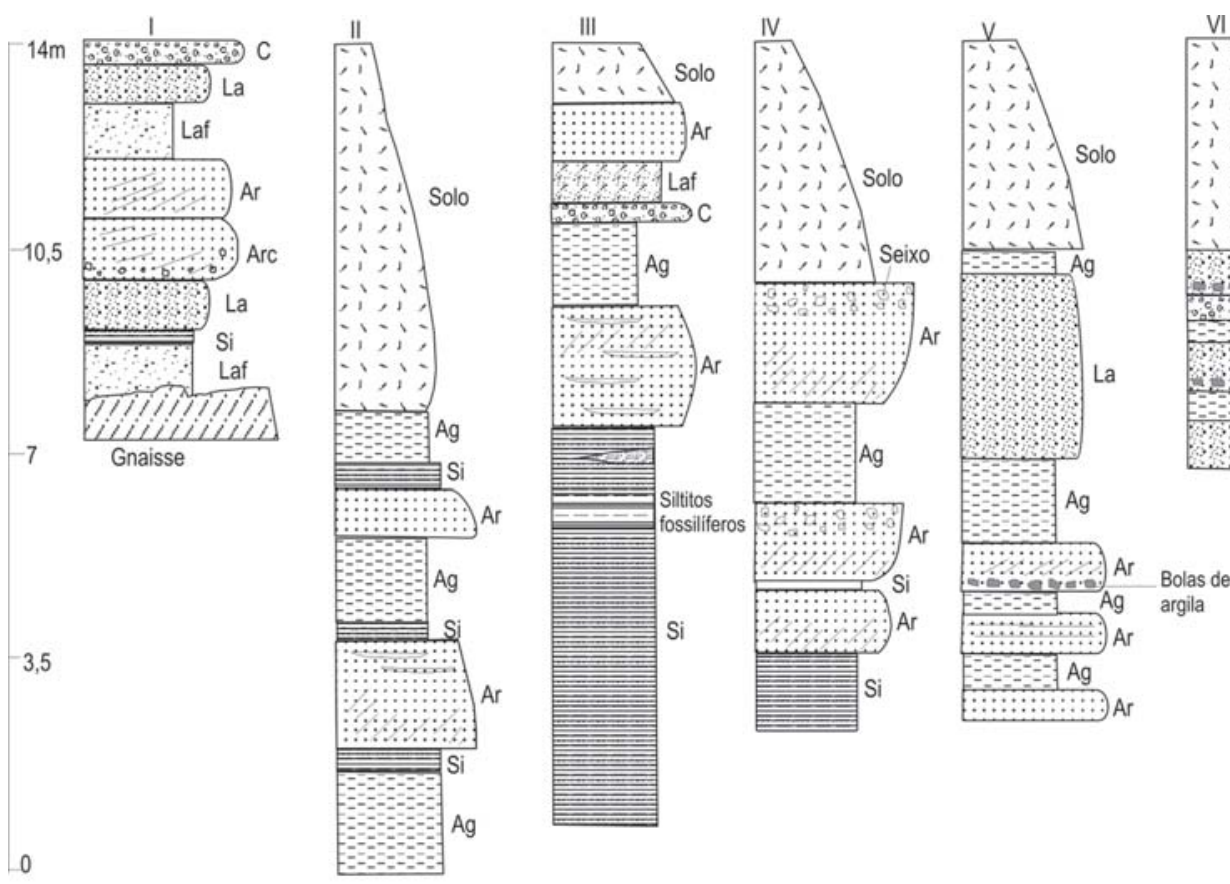

FIGURA 3 - Associação de fácies da Formação Rio Claro. Os perfis I e II (afloramentos PP98 e PP44) são de afloramentos localizados a oeste e nas proximidades da cidade de Jaguariúna, III e IV (afloramentos PP166 e PP174), nas proximidades de Paulínia, V próximo ao aeroporto de Viracopos e VI, a Indaiatuba (afloramentos CP111 e VU48). 
arenitos grossos ou conglomeráticos (Figura 3); (2) apresentam situação estratigráfica semelhante à Trc, quando se consideram os demais depósitos cenozóicos; e (3) assim como a Trc, associam-se à Superfície Neogênica (MELO et al. 1997). A diferença mais importante da Trc, com relação aos depósitos descritos por NEVES (1999) e BISTRICHI (2001), seria que estes teriam o ambiente fluvial incipientemente desenvolvido ou ausente, respectivamente. Isto é provavelmente devido ao fato da sua deposição ter se dado sobre relevo mais acidentado, em domínio de rochas pré-cambrianas, o que explicaria a presença de ocorrências menores e isoladas.
3.1.2. Ocorrência e distribuição regional das fácies

As principais ocorrências da Trc associamse a colinas amplas de topos sub-horizontais, remanescentes da superfície original de agradação da Formação Rio Claro. A espessura total parece não ultrapassar os 30 m (FERNANDES 1997). A Trc se associa a dois níveis planálticos: um mais baixo com altitudes variando de 560 a $650 \mathrm{~m}$, e um mais elevado, variando de 650 a 780 m de altitude (Figura 4). O primeiro associa-se à área de afloramento da Bacia do Paraná e o segundo, às rochas pré-cambrianas. Os depósitos do nível

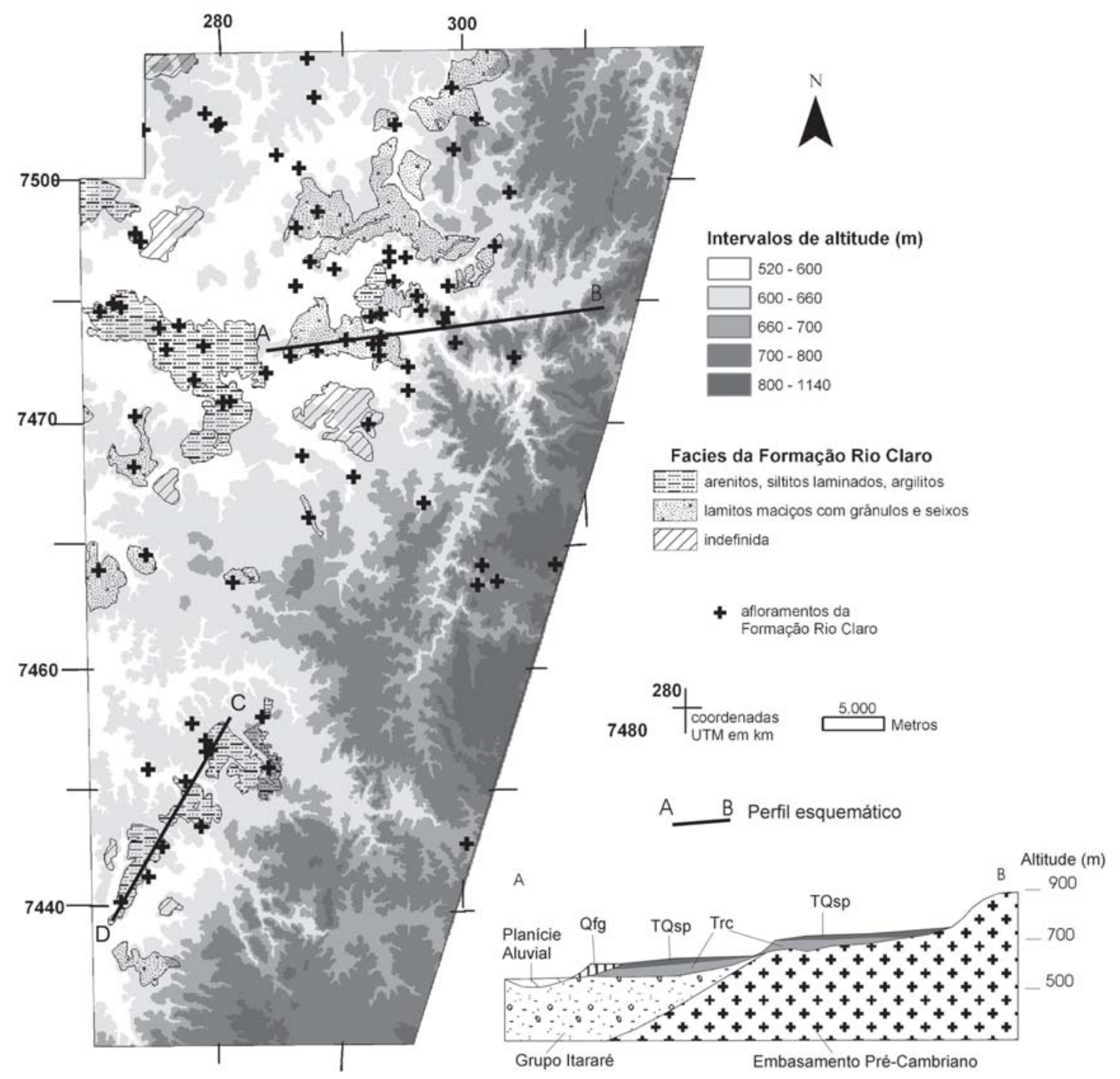

FIGURA 4 - Mapa das ocorrências de fácies de fluxos de detritos e de fácies fluviais da Trc, e perfis esquemáticos mostrando os níveis planálticos onde a formação ocorre. O traço CD corresponde à seção apresentada na figura 12. Algumas ocorrências aparecem apenas como pontos, pois não são mapeáveis na escala de trabalho (1:100.000). 
mais elevado são considerados como pertencentes à Trc pelo fato das suas fácies serem idênticas às da Trc do nível mais baixo, com amplo predomínio da La, e, também, por serem recobertos pela TQsp.

As menores altitudes da Trc (560 a 640m) ocorrem entre os rios Atibaia e Jaguari (Figura 1), onde a morfologia é caracterizada por colinas bastante amplas de topos aplainados. Aqui aparecem as suas maiores espessuras, com grande desenvolvimento das fácies fluviais de planícies de inundação que, próximo a Paulínia, podem atingir até cerca de 10m de espessura. Também é nesta região que a Formação Rio Claro se apresenta bastante ferruginizada, com desenvolvimento de couraças nas camadas mais permeáveis $(A r)$ e/ou no contato destas com as menos permeáveis ( $\mathrm{Si}$ e $\mathrm{Ag}$ ). A formação preferencial de couraças nesta região (entre Cosmópolis e Jaguariúna, passando por Paulínia) pode ser explicada pela presença de extensa superfície plana associada às planícies fluviais meandrantes, a qual representaria a superfície original de agradação da Trc. Neste caso os óxidos e hidróxidos de Fe teriam sido gerados por precipitação (MCFARLANE 1976), sob clima tropical de estações contrastadas.

Junto ao aeroporto de Viracopos e à cidade de Indaiatuba, as fácies fluviais também são bastante desenvolvidas e ocorrem entre as altitudes de 600 e $660 \mathrm{~m}$, associadas a colinas de topos aplainados; estas fácies são tectonicamente desniveladas, como será melhor descrito mais adiante. Observou-se, também, uma grande espessura da fácies $L a$, em contato late-

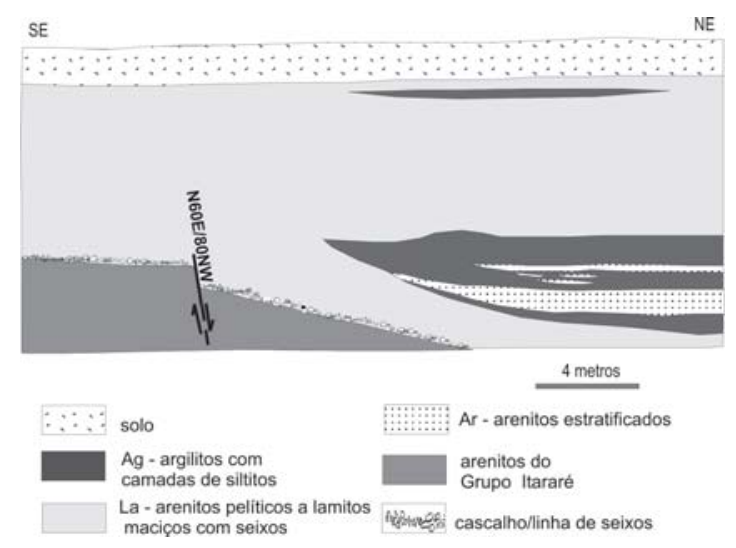

FIGURA 5 - Seção mostrando interdigitação das fácies de fluxos de detritos ( $L a$ - arenitos pelíticos a lamitos maciços com seixos esparsos) com as fácies de planícies fluviais (Ar, Ag, Si - arenitos, argilitos e siltitos) da Trc. Esta sobrepõe-se ao Grupo Itararé, sendo este contato marcado por linha de seixos e seccionado por falha NE de alto ângulo de mergulho. Esta falha é provavelmente transcorrente com componente normal e atribuível ao evento E2-EW. ral ou sobreposta aos depósitos fluviais. Estes, inclusive, apresentam uma terminação em cunha, que mostra a forma da planície aluvial interdigitada com os depósitos de fluxos de detritos (Figura 5). A fácies $A r$, nesta localidade, pode chegar a espessuras de no mínimo $8 \mathrm{~m}$, contendo camadas decimétricas de grande persistência lateral da fácies $A g$.

Junto ao embasamento cristalino, na região de Jaguariúna, a fácies $L a$ é bem mais freqüente e espessa, predominando sobre as demais. Localmente, pode apresentar mais de 10m de espessura, quando há superposição de vários fluxos de detritos. Isto indica a presença de relevos mais acidentados e uma maior proximidade em relação à fonte de detritos nesta região, durante a época de deposição (FERNANDES 1997). O transporte muito curto da fácies $L a$ fica evidente em alguns casos quando, na porção basal dos lamitos, se observam blocos de gnaisses alterados idênticos à rocha sobre a qual repousam; ou fragmentos de veios de quartzo alinhados, em continuidade com veios contidos nos gnaisses sotopostos. A presença de magnetita é importante nesta fácies quando localizada próximo a diabásios. Nestes casos as cores da fração argilosa também são mais escuras e arroxeadas. Próximo a Jaguariúna são comuns intercalações esparsas de lentes das fácies Si e Ag (representando áreas alagadas) na fácies $L a$, inclusive com presença de resquícios de fósseis vegetais.

A leste e nordeste de Jaguariúna, os lamitos maciços ocorrem em intervalo mais amplo de altitudes, variando de 600 a 780m, sobre as rochas précambrianas. Esta variação de altitude pode ser atribuída tanto a desnivelamentos topográficos existentes previamente à deposição da formação, como a desnivelamentos sindeposicionais ou posteriores, de natureza tectônica. Com relação aos desnivelamentos tectônicos, as seções geológicas construídas indicam que a soma dos rejeitos verticais das falhas pode chegar a pelo menos 50m (detalhado mais à frente).

Os solos formados sobre a Formação Rio Claro, principalmente sobre a fácies $L a$, são bastante espessos, de cor escura avermelhada, por vezes contendo grande quantidade de opacos e, por isso, assemelhando-se bastante aos solos dos diabásios. Estas espessuras são provavelmente devidas à grande porosidade e permeabilidade dos lamitos, o que permite infiltração e circulação rápida das águas pluviais.

3.1.3. Relações estratigráficas, idade e paleoclima

A Trc assenta-se sobre rochas do Grupo Itararé, diabásios ou gnaisses e granitos do embasamento cris- 
talino. É comumente sobreposta pela cobertura TQsp e, localmente, em contato erosivo, pela Qfg, ambas descritas a seguir. A fácies La, quando assentada diretamente sobre as rochas do embasamento da Trc, apresenta linha de seixos basal. A constituição dos seixos depende da natureza das rochas subjacentes, podendo ser arredondados, quando provenientes de seixos previamente contidos no Grupo Itararé, ou angulosos, de quartzo e subordinadamente de gnaisse ou granito, quando sobrepostos às rochas pré-cambrianas.

À Formação Rio Claro já foram atribuídas idades variando do Mioceno até o Holoceno, com base em critérios geomorfológicos, fossilíferos (principalmente vegetais) e tectônicos. Dados palinológicos e paleobotânicos de BISTRICHI (2001) indicam idade do Eoceno Superior-Oligoceno Inferior para a seqüência terciária mais antiga da região de AtibaiaBragança Paulista, e do Mioceno Superior, para a seqüência mais jovem correlacionável à Trc.

Com relação ao clima contemporâneo à deposição, existem alguns dados divergentes. MELO et al. (1997), com base em evidências mineralógicas, considera que a Trc tenha se depositado sob clima tropical úmido. BISTRICHI (2001) apresenta dados palinológicos e paleobotânicos que indicam condições temperadas, com estações bem definidas para a seqüência do Mioceno Superior, na região de Atibaia-Bragança Paulista. NEVES (1999) conclui que o clima era seco devido ao predomínio de ambiente de leques aluviais. No entanto, o pleno desenvolvimento de fácies de ambiente fluvial meandrante na região de Campinas sugere clima úmido ou de alternância de estações chuvosa e seca. Acredita-se que o predomínio das fácies de leques aluviais na região de Jundiaí seja devido à existência de um relevo mais acidentado, com sedimentação relacionada a movimentações tectônicas, e não a um clima preponderantemente seco. Estas interpretações contrapõem-se às de outros autores que acreditam que depósitos correlacionáveis à Trc teriam se depositado concomitantemente à elaboração de superfícies pedimentares, em clima semi-árido (BJÖRNBERG \& LANDIM 1966, CARVALHO et al. 1967, CHRISTOFOLETTI 1968 NAKASHIMA 1973, PENTEADO 1976). No entanto, PENTEADO (1976) ainda considerou que a sedimentação da Formação Rio Claro teria sido controlada por falhas, e que as bacias formadas seriam alveolares e escalonadas.

\subsection{Cobertura de superfícies aplainadas (TQsp)}

A cobertura de superfícies aplainadas, TQsp, ocorre sobre todas as unidades geológicas mais antigas da região estudada. A distribuição é ampla, porém descontínua, e as espessuras, com grande variação lateral, não ultrapassam os 3 a 4 metros, muitas vezes não chegando a 1 metro. Por este motivo, a representação da TQsp nas escalas 1:50.000 ou 1:100.000 é bastante difícil. No entanto, é possível mapear domínios onde ela ocorre mais generalizadamente e outros onde tende a não ocorrer, como representado na figura 6. Em geral, a cobertura TQsp ocorre nos topos de colinas e morros alongados e nas ombreiras planas ou de caimento suave, e está ausente nas encostas íngremes e nas áreas de campos de matacões. Da mesma forma que a Trc, associa-se aos níveis planálticos cujas altitudes variam de 550 a 650 e 650 a $780 \mathrm{~m}$.

A TQsp consiste em material areno-argiloso a arenoso, com pouca argila, e contém grânulos e seixos angulosos e esparsos de quartzo. Na base, é típica a ocorrência de linha de seixos ou cascalheira, constituídas de seixos angulosos de quartzo e/ou seixos arredondados. Estes últimos são provenientes de

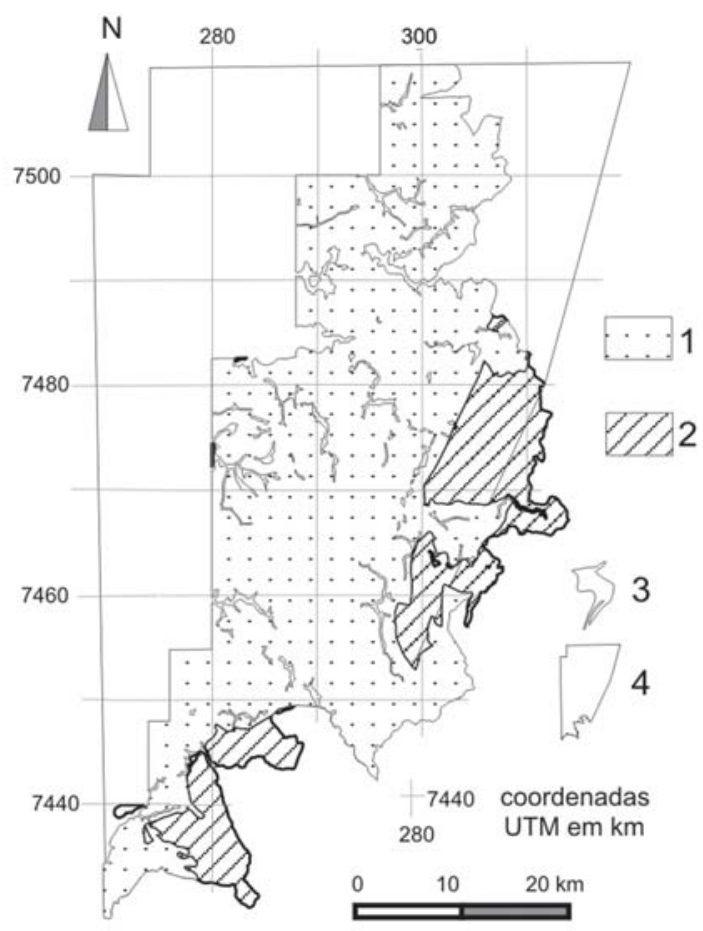

FIGURA 6 - Domínios onde a cobertura de superfícies aplainadas (TQsp) tende a ocorrer ou estar ausente (modificado de INSTITUTO GEOLÓGICO 2002). (1) Domínio onde a cobertura TQsp tende a ocorrer, (2) Domínio onde a cobertura TQsp tende a estar ausente, (3) Planície aluvial, (4) Limite da área de estudo. 
retrabalhamento de seixos previamente contidos no Grupo Itararé e constituem-se, mais freqüentemente, de quartzo ou metarenito. Fragmentos ferruginizados originados a partir do desmantelamento das couraças ferruginosas formadas sobre a Formação Rio Claro também são bastante comuns. A matriz das cascalheiras varia desde argilosa até arenosa grossa com grânulos e pequenos seixos. As cascalheiras também podem apresentar granodecrescência ascendente.

Em termos de ocorrência, esta cobertura poderia ser correlacionável à Qrs de MELO et al. (2001), no entanto, existem diferenças importantes com relação a outras características: a Qrs apresenta espessura maior (entre 5 e 20m) e interdigita-se com depósitos aluviais de baixos terraços. A TQsp, aqui descrita é cobertura de topo e não se relaciona com depósitos de planícies aluviais atuais. MELO et al. (2001) admitem que a gênese da Qrs deve ter sido iniciada no Terciário.

\subsection{Depósitos de fluxos gravitacionais (Qfg)}

A Qfg foi claramente identificada em apenas alguns afloramentos, onde ocorre sobre as rochas pré-cambrianas, Grupo Itararé ou Formação Rio Cla-

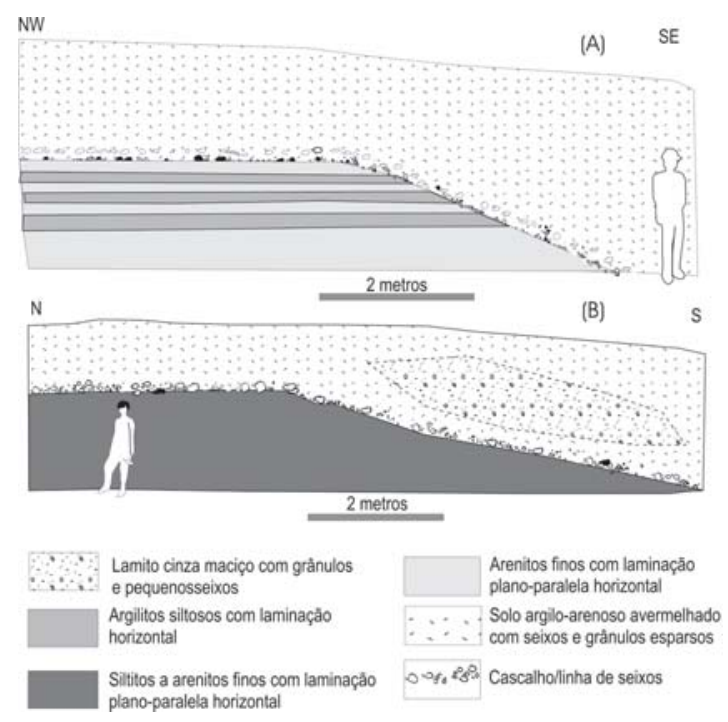

FIGURA 7 - Cobertura de fluxos gravitacionais (Qfg) sobreposta à Formação Rio Claro. Notar o espessamento da cobertura em direção aos vales atuais. Em (A) clastos ferruginizados, provenientes da Trc, ocorrem preferencialmente na base da linha de seixos e clastos de quartzo, no topo. Em (B) camada lenticular de lamitos acinzentados, muitos parecidos com a fácies $L a$ da Trc, passa gradativamente para o material avermelhado da Qfg. ro, e não é representável na escala aqui trabalhada. Está associada às formas de rampa, que mergulham em direção aos vales atuais. Associa-se ao nível planáltico de 550 a $650 \mathrm{~m}$ de altitude.

A constituição desta cobertura é dependente da natureza das rochas subjacentes. As ocorrências sobre a Trc correspondem a material avermelhado, argiloso a argilo-arenoso, com grânulos e seixos pequenos, esparsos e subangulosos, de quartzo. As espessuras máximas observadas são da ordem de 7 $\mathrm{m}$. Este material pode passar lateralmente a lamitos e arenitos pelíticos, maciços, de cor acinzentada, com seixos e grânulos, de provável retrabalhamento da fácies La da Trc. Depósitos de caráter fluvial (terraços) estão presentes sobre as rochas pré-cambrianas e correspondem a cascalhos intercalados com areia grossa a muito grossa. Os cascalhos contêm seixos de quartzo predominantemente angulosos e, subordinadamente, subarredondados, e podem apresentar granodecrescência ascendente. A areia, em camadas de espessuras decimétricas, apresenta matriz fina. Acima do cascalho, ou intercalando-se com ele, pode ocorrer material coluvial argilo-arenoso, ou arenoso pouco argiloso, castanho avermelhado, com grânulos de quartzo dispersos. Quando sobre arenitos do Grupo Itararé, a Qfg é arenosa, com grânulos e pequenos seixos esparsos, além de seixos basais.

A Qfg sobrepõe-se à Formação Rio Claro segundo contato erosivo (Figura 7), que é marcado por um pavimento de clastos bastante contínuo e expressivo. Este pavimento é constituído por seixos de quartzo subangulosos a angulosos, e seixos de argilitos, siltitos, arenitos grossos e conglomerados, todos ferruginizados, e provavelmente provenientes de porções encouraçadas e desmanteladas da Formação Rio Claro. Este desmantelamento pode ter sido anterior ou contemporâneo ao início da sedimentação dos depósitos Qfg, e teria se dado sob clima tropical úmido ou árido (TARDY 1993).

O espessamento da Qfg em direção aos vales atuais, observado junto a drenagens importantes da região (ribeirão Pirapitingui e rio Atibaia, figuras 7A e B respectivamente), aparentemente em continuidade com as atuais planícies aluviais, indica sua formação em paisagem próxima da atual. Por este motivo, esta unidade foi atribuída ao Quaternário.

Entre 1 e 2 m de profundidade, estes depósitos apresentam fragmentos de carvão, coletados em duas localidades e que forneceram as seguintes idades: $7070 \pm 190$ e $6400 \pm 160$ anos AP(FERNANDES 1997). Estes dados estão no intervalo, de 6500 a 8500 anos AP, de tendência de concentração das idades obti- 
das por MELO et al. (1997) em depósitos quaternários colúvio-eluviais (Qce) e em regolitos da Depressão Periférica. É possível que estes materiais, pelo seu posicionamento no topo do perfil de alteração e em encostas de colinas, já sejam produto de fluxo gravitacional de detritos posteriores aos depósitos Qfg e, portanto, seriam materiais mais jovens.

\section{ESTRUTURAS DEFORMADORAS E EVOLUÇÃO TECTÔNICA}

Na região de estudo foram identificadas estruturas, que afetam as coberturas cenozóicas, atribuíveis aos eventos E2-EW e E3-NW de FERNANDES (1997) e FERNANDES \& AMARAL (2002) (Tabela 2). Também foram identificadas fraturas de um último evento tectônico de provável regime extensional.

Nota-se que existem duas áreas onde as fácies fluviais da Trc foram bem desenvolvidas: entre Cosmópolis e Jaguariúna, passando por Paulínia, e junto a Indaiatuba e aeroporto de Viracopos. Como pode ser observado na figura 4 , estas são separadas por uma área topograficamente elevada onde ocorrem pequenas ocorrências isoladas de fácies de fluxos de detritos, a oeste de Campinas. Apesar de não ser possível descartar a hipótese do desnivelamento ter sido erosivo e prévio à sedimentação da Trc, o balizamento deste alto topográfico, por descontinuidades de direção NW e NE, como sugerido pela conformação das curvas topográficas (FERNANDES \& AMARAL 2002), sugere que esta região tenha funcionado como um alto estrutural, controlado tectonicamente durante a época de deposição da Trc. Na área entre os rios Atibaia e Jaguari, FERNANDES (1997) e FERNANDES \& AMARAL (2002) também descreveram estruturas do evento E2EW sintectônicas à deposição da Trc. Nesta mesma área ocorrem lineamentos extensos, de direções ao redor de N70-50W e N50-60E, relacionáveis às falhas transcorrentes do evento citado. Falha de direção NE de mergulhos elevados e deslocamento com componente vertical normal, afetando a base da Formação Rio Claro (Figura 5), próximo ao Aeroporto de Viracopos, também são correlacionáveis ao evento transcorrente com componente extensional E2-EW da tabela 2.

Falhas de direção WNW, de rejeitos verticais, no mínimo métricos, colocam lado a lado sedimentos atribuíveis à Trc, muito imaturos e rudáceos, de no mínimo 5m de espessura, e gnaisses da Nappe Socorro-Guaxupé (Figura 8). Aqui a Trc é superposta

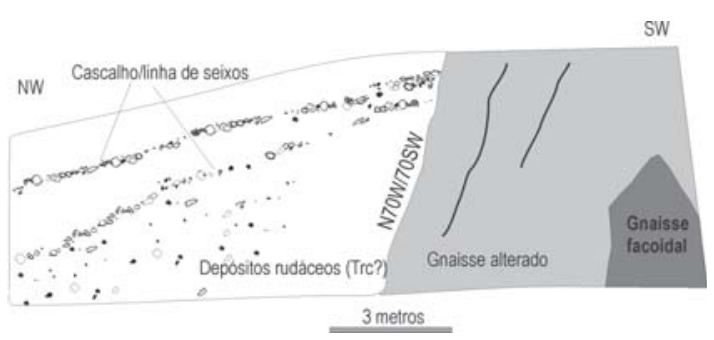

FIGURA 8 - Falha WNW (N70W), relacionável ao evento E2-EW, condicionando a presença de depósitos rudáceos atribuíveis à Formação Rio Claro. Este afloramento localizase na lente gnáissica de Joaquim Egídio, onde outras ocorrências atribuíveis à Trc, e constituídas da fácies $L a$, também foram verificadas.

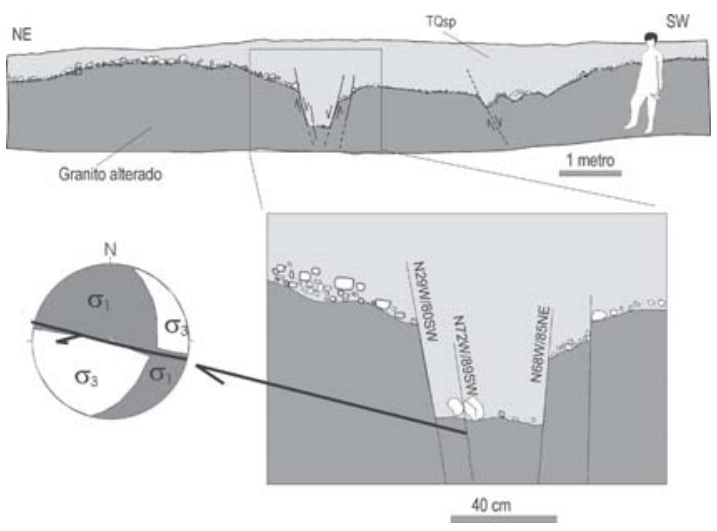

FIGURA 9 - Falhas EW a WNW e NNW, de mergulhos elevados, que afetam a cobertura TQsp. Os rejeitos apresentam componentes de deslocamento normal da ordem de centímetros a decímetros e as estrias, junto com os sentidos de deslocamento, indicam que as falhas EW e WNW são dextrais oblíquas. Diagrama de diedros retos (ANGELIER \& MECHLER 1977) para a falha N72W/ 89SW, representada por um grande círculo, que contém estrias de atitude $\mathrm{N} 87 \mathrm{~W} / 44^{\circ}$, representada por uma seta que também indica o sentido de movimento. No diagrama estão representados os campos que contém $\sigma 1$ e $\sigma 3$. Estas estruturas são compatíveis com o evento E3-NW.

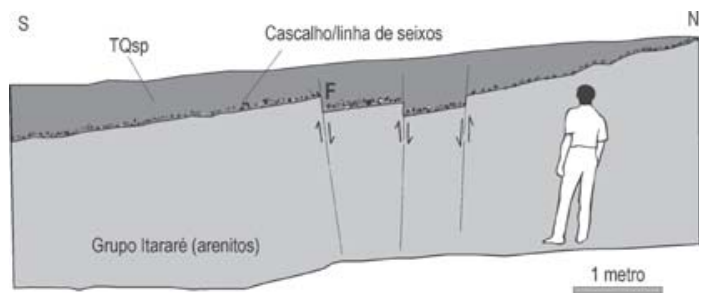

FIGURA 10 - Cobertura areno-argilosa (TQsp) sobre arenitos do Grupo Itararé apresentando linha de seixos na base, sendo cortada por falhas provavelmente transcorrentes, com componentes normais, de atitude N88E/88NW (F) do evento E3-NW. 
por linha de seixos relacionável à TQsp, que também é afetada pela falha. Esta estrutura, devido à sua direção, mergulho e componente extensional, e também pelo fato de cortar a TQsp, é mais provavelmente relacionável ao evento E3-NW (Tabela 2).

Próximo a Indaiatuba foram observadas falhas que afetam a cobertura TQsp. A direção destas estruturas varia de EW a WNW, subordinadamente NNW, e os mergulhos são elevados. Os rejeitos apresentam componentes de deslocamento normal da ordem de centímetros a decímetros e as estrias, junto com os sentidos de deslocamento, indicam que as falhas EW e WNW são dextrais oblíquas (Figuras 9 e 10). A figura 9 mostra falhas transcorrentes oblíquas cujas componentes de deslocamento vertical geraram um graben. São compatíveis com o evento E3-NW, definido por FERNANDES (1997) e FERNANDES \& AMARAL (2002), cujo campo de esforços é de regime transcorrente, com $\sigma 1$ horizontal de direção NW (Tabela 2).

Na região próxima a Pedreira e Jaguariúna, a cobertura TQsp é comumente afetada por falhas de direção ao redor de N50E, com rejeitos e mergulhos compatíveis com falhas normais (Figura 11). O material arenoso não propicia a geração e registro de estrias. Estas estruturas podem ser relacionadas a falhas normais de direção NE, que afetam a Forma- ção Rio Claro próximo a Cosmópolis, descritas por FERNANDES (1997) e FERNANDES \& AMARAL (2002). Neste local, as relações de superposição indicam que são posteriores às estruturas geradas pelo evento E4-NS, que, por sua vez, se superpõem às estruturas do evento E3-NW. Todas estas estruturas cortam a Formação Rio Claro. Para estes autores, as falhas normais NE teriam sido geradas pelo evento E5-NNE de regime transcorrente; no entanto, parece mais provável que o evento que as gerou, o mais jovem da área de estudo, seja de regime extensional e não transcorrente, com base nas seguintes considerações:

- o campo de esforços relacionado ao evento E5NNE levaria à geração de falhas transcorrentes de direção ao redor de N50-60E e, portanto, não poderia gerar falhas puramente normais de mesma direção;

- fraturas de cisalhamento conjugadas do evento E5-NNE, cortando depósitos cenozóicos, foram verificadas em apenas um afloramento por FERNANDES (1997) e FERNANDES \& AMARAL (2002). Neste afloramento, fraturas sub-verticais de direção NNW e ENE cortam os depósitos Qfg aqui descritos. Estas fraturas poderiam ser atribuídas a uma variação local da ori-

\section{(A) Cascalho/linha de seixos}

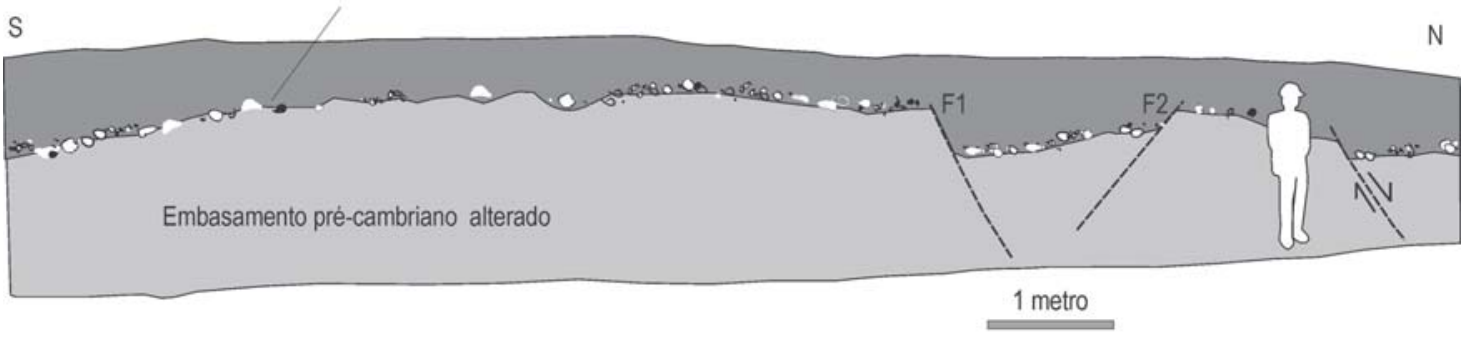

(B)

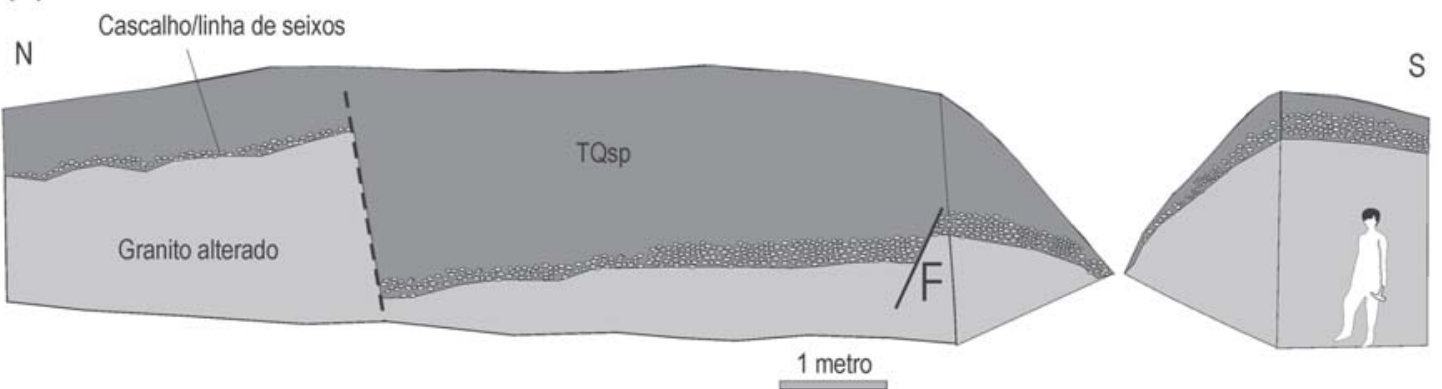

FIGURA 11 - Cobertura TQsp sobre embasamento alterado, sendo seccionada por falhas do evento E5-NE. (A) A linha de seixos é cortada por falhas provavelmente normais de atitude ao redor de N55E/71NW (F1) e N50E/55SE (F2). (B) Gráben assimétrico delimitado por falhas NE. A cobertura TQsp é delimitada na base por cascalheira, constituída de seixos arredondados. A falha F é provavelmente normal e de atitude N48E/63NW. 
entação dos esforços do evento E4-NS, também transcorrente.

- As falhas normais de direção NE não ocorrem associadas a falhas transcorrentes, o que seria de se esperar caso o regime que as tivesse gerado fosse transcorrente.

Falhas normais de direção ao redor de N5070 E cortando a Formação Rio Claro, descritas por FERNANDES (1997) ao sul do Aeroporto de Viracopos e atribuídas ao evento E2-EW (ponto CP275), são aqui reinterpretadas como do evento E5-NE, pois desnivelam tectonicamente a superfície de agradação da Trc nesta região, como ilustrado na figura 12. Estas falhas de direção NE-ENE parecem ter produzido deslocamentos da ordem de $20 \mathrm{~m}$ que, muito provavelmente, resultam da soma de vários rejeitos de menores dimensões, parcialmente observados em afloramentos.

A figura 12 também mostra a base deposicional da Trc sendo desnivelada por falhas relacionáveis ao evento E3-NW, de direções WNW, NNW e NW, e deduzidas a partir dos deslocamentos verticais da Trc observados em afloramentos e a partir da construção dos perfis, junto com a análise de lineamentos.

Apesar de estrias de falha terem sido medidas em apenas um afloramento, os mergulhos e rejeitos das falhas medidas já são fortes indicativos do regime tectônico e campos de esforços associados. Isto ocorre pelo fato das estruturas que afetam as coberturas cenozóicas serem neoformadas, ou seja, não aproveitaram planos préexistentes pois estes não existiam. Desta forma, as falhas próximas a EWWNW, por apresentarem mergulhos sempre superiores a $80^{\circ}$, são provavelmente transcorrentes e portanto, $\sigma 1$ e $\sigma 3$ são horizontais. Apresentam componente vertical, indicada pelos rejeitos observados e pelo mergulho de estria medida (Figura 9). $\sigma 1$ apresenta direção NW, como comprovado por rejeito dextral verificado em afloramento. Por outro lado, as falhas NE-ENE apresentam mergulhos médios (menores que $70^{\circ} \mathrm{e}$, em geral, entre $60^{\circ} \mathrm{e} 50^{\circ}$ ), e rejeitos verticais, por vezes bem marcados. Assim são interpretadas como falhas normais, ou seja, $\sigma 3$ é horizontal e perpendicular à direção da falha e $\sigma 1$ é vertical. Estruturas claramente correlacionáveis a estas foram descritas por FERNANDES (1997) e FERNANDES \& AMARAL (2002). Nestes trabalhos foi apresentado um grande número de estruturas, inclusive com estrias, as quais afetam diabásios cretáceos, a Formação Rio Claro, a TQsp e, em parte, a Qfg.

Segundo ASSUMPÇÃO (1998), a direção de SHmax para o Cráton do São Francisco e Faixa Brasília adjacente é ENE. Os mecanismos focais, da sismicidade relacionada a este SHmax, e falhas recentes, de natureza normal, transcorrente e reversa, indicam que o regime tectônico atual, em regiões distantes da costa, seria transcorrente (ASSUMPÇÃO 1998). Neste caso, a situação observada em Campinas poderia representar a presença,

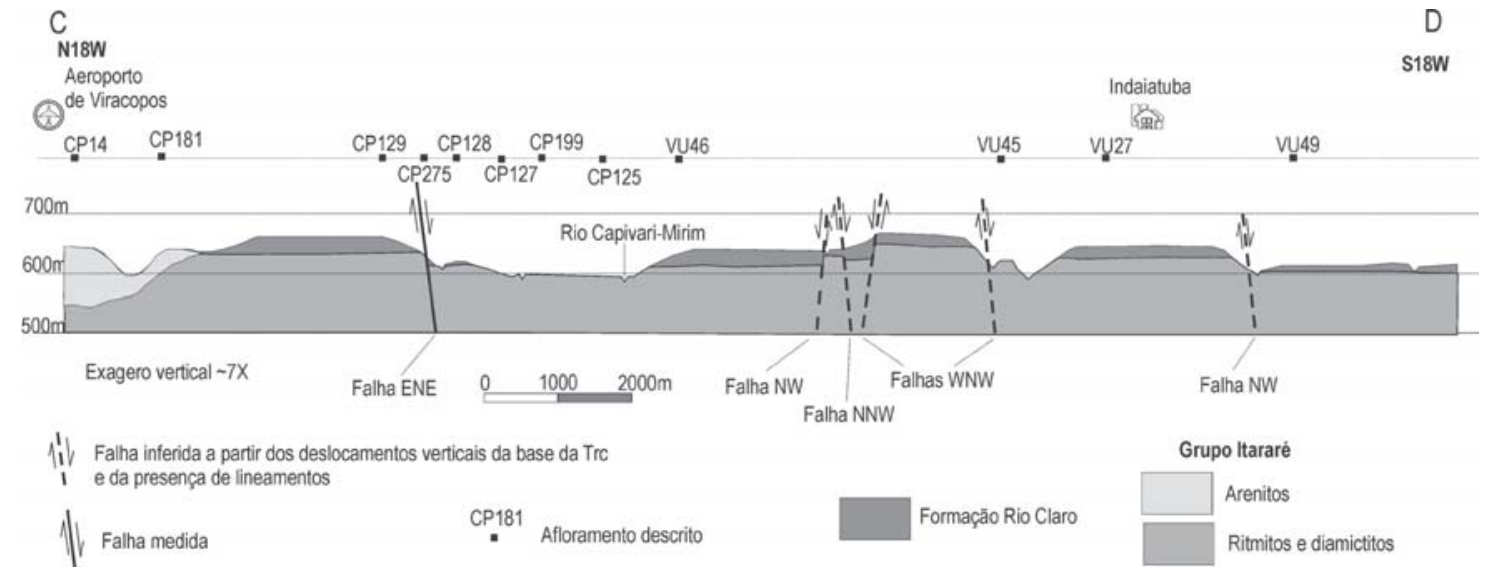

FIGURA 12 - Seção mostrando os desnivelamentos tectônicos da superfície da base deposicional (e de agradação) da Trc. As falhas representadas no perfil foram deduzidas a partir das altitudes do contato basal da Trc com o Grupo Itararé em afloramentos, de dados estruturais de campo e da interpretação de lineamentos. Notar que os desnivelamentos são causados principalmente por falhas de direção WNW, NW, NNW, relacionáveis ao evento E3-NW e, subordinadamente, por falhas ENE, do evento E5-NE. 
nesta região, de uma área com predomínio de esforços extensionais, dentro de uma região maior onde o regime tectônico seria o transcorrente.

\section{CONCLUSÕES}

Na região de estudo ocorrem 3 depósitos cenozóicos de topo e encosta que correspondem, do mais antigo ao mais jovem, à Formação Rio Claro (Trc) e às coberturas TQsp e Qfg. A Trc constitui-se de fácies de ambiente fluvial meandrante e fácies de fluxos gravitacionais, as quais ocorrem intercaladas ou em contato lateral. A TQsp, com espessuras que não ultrapassam os 3 a $4 \mathrm{~m}$, ocorre nos topos de colinas e morrotes e nas ombreiras planas de caimento suave. Constitui-se de material areno-argiloso a arenoso com linha de seixos na base. A Qfg é de ocorrência restrita, associa-se a formas de rampa, e espessa-se em direção aos vales atuais, podendo atingir $7 \mathrm{~m}$ de espessura. A sua constituição é dependente da natureza da rocha sobre a qual repousa, podendo se tratar de material de fluxos gravitacionais ou de terraços fluviais. Apresentam linha de seixos basal composta por clastos ferruginizados que se originaram das couraças ferruginosas desenvolvidas sobre os depósitos da Trc.

As fácies fluviais da Trc apresentam-se mais desenvolvidas entre as cidades de Jaguariúna e Cosmópolis, passando por Paulínia, e junto a Indaiatuba e aeroporto de Viracopos. Nestas duas áreas a Trc está associada a colinas amplas de topos planos, remanescentes da superfície original de agradação desta formação. A ferruginização das fácies mais permeáveis da Trc foi intensa nestas áreas e explica-se pela presença de superfície plana e mais rebaixada associada à superfície de agradação da Trc (Superfície Neogênica).

$\mathrm{Na}$ área foram identificadas estruturas de três eventos tectônicos cenozóicos, dois dos quais já haviam sido descritos na literatura. O mais antigo (E2-EW) é de regime transcorrente (provavelmente transtensional), com $\sigma 1$ de orientação aproximada EW. Foi provavelmente contemporâneo à deposição da Trc e originou falhas transcorrentes de direção NE e NW e falhas normais de direção ao redor de EW. O evento seguinte (E3-NW), de regime transcorrente e com $\sigma 1$ de direção NW, produziu falhas EW/WNW e NS/NNW transcorrentes com componente normal. Este evento afeta a Trc e a TQsp e produziu desnivelamentos tectônicos da Trc da ordem de 20m. O evento mais jovem na área de estudo é de regime extensional, com $\sigma 3$ de direção NE, e gerou falhas normais que cortam a Trc e a TQsp. Também produziu desnivelamentos topográficos que afetam a superfície da base da Trc. Este evento é compatível com o SHmax identificado para o sul do Cráton do São Francisco, que está ao redor da direção ENE, possívelmente relacionado a um regime transcorrente regional que, na área de estudo, produziu estruturas compatíveis com regime extensional.

A Trc ocorre em dois níveis planálticos: um mais baixo, associado à área de afloramento da Bacia do Paraná, com altitudes variando de 560 a 650m, e um mais elevado, variando de 650 a 780 m de altitude, na área de ocorrência das rochas pré-cambrianas. Observou-se que a atividade tectônica posterior à deposição da Trc produziu desnivelamentos de pelo menos $50 \mathrm{~m}$. No entanto, não é possível descartar que a variação total de altitudes, dentro de cada nível planáltico, tenha sido também resultante da atuação de outros fatores, tais como a conformação pretérita do relevo e atividade tectônica sincrônica à sua deposição.

\section{AGRADECIMENTOS}

À FAPESP (Processo 94/01303-4), ao INSTITUTO GEOLÓGICO e ao FEHIDRO (Processo 030/ 99, CBH-PCJ 003/98) pelos suportes financeiro e de infra-estrutura.

\section{REFERÊNCIAS BIBLIOGRÁFICAS}

ANGELIER, J. \& MECHLER, P. 1977. Sur une méthode grafique de recherche des constraintes principales également utilisable en téctonique et en seismologie: la méthode des diedres droits. Bulletin Societe Geologique de France, 7:1309-1318.

ASSUMPÇÃO, M. 1998. Focal mechanisms of small earthquakes in the southeastern Brazilian shield: a test of stress models of the South American Plate. Geophysical Journal International, 133:490-498.

BASEI, M.A.S.; CAMPOS NETO, M.C.; BERGMANN, M.; FIGUEIREDO, M.C.H. 1986. Geologia da Folha Amparo. São Paulo. PróMinério/USP. V.1 (Geologia). 109p. 
BISTRICHI, C.A. 2001. Análise estratigráfica e geomorfológica do Cenozóico da região de Atibaia-Bragança Paulista, Estado de São Paulo. Instituto de Geociências e Ciências Exatas, Universidade Estadual Paulista, Rio Claro, Tese de Doutoramento, 135p.

BJÖRNBERG, A.J.S. 1965. Sedimentos pós-cretácicos do leste do Estado de São Paulo. Escola de Engenharia de São Carlos, Universidade de São Paulo, São Carlos, Tese de Livre-Docência, 133 p.

BJÖRNBERG, A.J.S. \& LANDIM, P.M.B. 1966. Contribuição ao estudo da Formação Rio Claro, Neocenozóico. Boletim da Sociedade Brasileira de Geologia, 15(4):43-68.

BJÖRNBERGA.J.S.; GANDOLFI, N; PARAGUASSU, A.B. 1971. Basculamentos tectônicos modernos no Estado de São Paulo. In: SBG, CONGRESSOBRASILEIRODEGEOLOGIA, 25, São Paulo, Anais, 2:159-174.

CAMPANHA, G.A.C.; RICCOMINI, C.; MELO, M.S.; HASUI, Y.; ALMEIDA, F.F.M.; DEHIRA, L.K. 1985. Análise do padrão de fraturamento mesozóico-cenozóico de bacias tafrogênicas continentais do sudeste do Brasil. In: SBG, SIMPÓSIOREGIONAL DE GEOLOGIA, 5, São Paulo, Atas, 1:337-350.

CAMPOS NETO, M.C. 1990. A porção ocidental da Faixa Alto Rio Grande -ensaio de evolução tectônica. São Paulo. Instituto de Geociências, Universidade de São Paulo, São Paulo, Tese de Doutoramento , 210 p.

CAMPOS NETO, M.C.; BASEI, M.A.S.; ALVES, F.R.; FIGUEIREDO, M.C.H. 1984. Geologia da Folha Bragança Paulista, 1:50.000. Relatório Final, São Paulo, Convênio IG-USP/PRÓ-MINÉRIO, v. 1, 162p. (Inédito).

CARVALHO, A., MELFI, A.J., BITTENCOURT, I, QUEIROZ NETO, J.P., NAKASHIMA, P. 1967. Sedimentos neo-cenozóicos na área de Campinas, Estado de São Paulo. In: SBG, CONGRESSO BRASILEIRO DE GEOLOGIA, 21, Curitiba, Anais, 58-70.

CAVALCANTE, J.C.; CUNHA, H.C.S.; CHIEREGATI, L.A.; KAEFER, L.Q.; ROCHA, J.M.; DAITX, E.; RAMALHO, R. 1979. Projeto Sapucaí, Re- latório Final, MME/DNPM, Série Geologia 4, Secção Geológica Básica 2, 299p.

CHRISTOFOLETTI, A. 1968. O fenômeno morfogenético no Município de Campinas. São Paulo. Faculdade de Filosofia, Ciências e Letras, Universidade de Campinas, Rio Claro, Tese de Doutoramento, 209 p.

CORDANI, U.G.; NEVES, B.B.B.; FUCK, R.A.; PORTO, R.; THOMAZ FILHO, A.; CUNHA, F.M.B. 1984. Estudo preliminar de integração do Pré-cambriano com os eventos tectônicos das bacias sedimentares brasileiras. PETROBÁS-CENPES-SINTEP, Rio de Janeiro, 70 p. (Boletim Ciência-Técnica-Petróleo, 15)

DE MARTONNE, E. 1943. Problemas morfológicos do Brasil tropical atlântico. Revista Brasileira de Geografia, 5(4): 523-550.

FERNANDES, A.J. 1997. Tectônica Cenozóica na Porção Média da Bacia do Rio Piracicaba e sua aplicação à hidrogeologia. Instituto de Geociências, Universidade de São Paulo, São Paulo, Tese de Doutoramento, 244p.

FERNANDES, A.J. \& AMARAL, G. 2002. Cenozoic tectonic events at the border of the Parana Basin, São Paulo, Brazil. Journal of South American Earth Sciences, 14(8):911-931.

FERNANDES, A.J.; FITTIPALDI, F.C.; FERREIRA, C.J. 1994. Faciologia dos depósitos cenozóicos entre Jaguariúna e Americana-SP. In: SBG, CONGRESSO BRASILEIRO de GEOLOGIA, 38, Camboriú, Anais, 3: 269-270.

FERNANDES da SILVA, P.C. 1998. Tectônica rúptil da região entre Pilar do Sul e Votorantim, SP. Revista Brasileira de Geociências, 28(4): 485494.

FERREIRA, F.J.F.; MORAES, R.A.V.; FERRARI, M.P.; VIANNA, R.B. 1981. Contribuição ao estudo do lineamento estrutural de Guapiara. In: SBG, SIMPÓSIO REGIONAL DE GEOLOGIA, 3, Curitiba, Atas, 1:226-240.

FÚLFARO, V.J. \& SUGUIO, K. 1968. AFormação Rio Claro, neocenozóico, e seu ambiente de deposição. São Paulo, OIGG, 20:45-60. 
FÚLFARO, V.J.; SAAD, A.R.; SANTOS, M.V.; VIANNA, R.B. 1982. Compartimentação e evolução tectônica da Bacia do Paraná. Revista Brasileira de Geociências, 12(4):590-611.

GARDA, G.M. 1995. Diques básicos e ultrabásicos da região costeira entre as cidades de São Sebastião e Ubatuba, Estado de São Paulo. Instituto de Geociências, Universidade de São Paulo, São Paulo, Tese de Doutoramento, $156 \mathrm{p}$.

HASUI, Y.; DANTAS, A.S.; CARNEIRO, C.D.R.; BISTRICHI, C.A. 1981. O Embasamento PréCambriano e Eopaleozóico em São Paulo. In: Instituto de Pesquisas Tecnológicas, Mapa Geológico do Estado de São Paulo, PRÓ-MINÉRIO/PROMOCET, São Paulo, p. 12-45.

HASUI, Y; FACINCANI, E.M.; SANTOS, M.; JIMENEZ-RUEDA, J.R. 1995. Aspectos estruturais e neotectônicos na formação de boçorocas na região de São Pedro, SP. Rio Claro: Geociências, 14(2):59-76.

HIRUMA, S.T.; RICCOMINI, C.; MODENESIGAUTTIERI, M.C. 2001. Neotectônica no Planalto de Campos do Jordão, SP. Revista Brasileira de Geociências, 31(3): 375-384.

INSTITUTO GEOLÓGICO. 1993. Subsídios do meio físico-geológico ao planejamento do Município de Campinas (SP). Instituto Geológico - SMASP, São Paulo, Relatório Técnico, 2: 139-221.

INSTITUTO GEOLÓGICO.1995. Subsídios ao planejamento regional e urbano do meio físico na porção média da Bacia do Rio Piracicaba. Instituto Geológico-SMA, São Paulo, Relatório Técnico, 3: 290-372.

INSTITUTO GEOLÓGICO. 2002. Mapeamento da vulnerabilidade natural dos aquíferos fraturados pré-cambrianos da Região Metropolitana de Campinas. Instituto Geológico-SMA/ FEHIDRO, São Paulo, Relatório técnico, 81 p, 6 mapas anexos.

MACEDO, J.M. 1990. Evolução tectônica da Bacia de Santos e áreas continentais adjacentes. In: G.P. Raja Gabaglia \& E.J. Milani (coords.) Origem e Evolução de Bacias Sedimentares, PETROBRÁS, Rio de Janeiro, p.361-376.
MC FARLANE, M.J. 1976. Laterite and landscape. Academic Press. $151 \mathrm{p}$.

MELO, M.S. 1990. A Formação Pariquera-Açu e depósitos relacionados: sedimentação, tectônica e geomorfogênese. Instituto de Geociências, Universidade de São Paulo, São Paulo, Dissertação de Mestrado, 211 p.

MELO, M. S.; STEIN, D.P.; PONÇANO, W.L.; BISTRICHI, C.A. 1993. Neotectônica da área do Alto Rio Pardo (SP e MG). Revista do Instituto de Geociências, 14(1):27-38.

MELO, M.S; COIMBRA, A.M.; CUCHIERATO, G. 1997. Facies sedimentares da Formação Rio Claro, neocenozóico da Depressão Periférica Paulista. São Paulo: Revista do Instituto Geológico, 18(1/2): 49-63.

MELO, M.S; COIMBRA,A.M.; CUCHIERATO, G. 2001. Genesis of Quaternary sedimentary covers in Southeastem Brazil. Quatemaire, Paris, 12:179-188.

NAKASHIMA, P. 1973. Estudo das formações superficiais na área de Campinas - Viracopos (SP): suas relações com a evolução geomorfológica e os solos. Faculdade de Filosofia, Letras e Ciências, Universidade de São Paulo, São Paulo, Dissertação de Mestrado, 149 p.

NEVES, M. 1999. Evolução cenozóica da região de Jundiaí. Instituto de Geociências e Ciências Exatas, Universidade Estadual Paulista, São Paulo, Dissertação de Mestrado, 135 p.

PELLOGIA, A.U.G. 1990. A Faixa Alto Rio Grande na região de Amparo. Instituto de Geociências, Universidade de São Paulo, São Paulo, Dissertação de Mestrado, 124p.

PENTEADO, M.M. 1976. Geomorfologia do setor centro-ocidental da depressão periférica paulista. Instituto de Geografia, Universidade de São Paulo, São Paulo, Série Teses e Monografias 22, 86 p.

PIRES NETO, A.G. 1996. Estudo morfotectônico das bacias hidrográficas dos rios Piracicaba, Capivari, Jundiaí e áreas adjacentes no Planalto Atlântico e Depressão Periférica. Instituto de Ciências Exatas, Universidade Estadual Paulista, Rio Claro, Relatório de Projeto de PósDoutoramento, 76 p. 
PORTELA FILHO, C.V. 2003. Condicionamento estrutural-magnético do sistema aqǘfero Serra Geral na região central do Arco de Ponta Grossa (Bacia do Paraná) e sua conectividade com sistema Aqüífero Guarani. Departamento de Geologia, Universidade Federal do Paraná, Curitiba, Dissertação de Mestrado, $128 \mathrm{p}$.

RICCOMINI, C.; PELLOGIA,A.U.G; SALONI, J.C.L., KOHNKE, M.W.; FIGUEIRA, R.M. 1989. Neotectonic activity in the Serra do Mar Rift System (southeastern Brazil). Journal of South American Earth Sciences, 2:191-197.

RICCOMINI, C 1997. Considerações sobre a posição estratigráfica e tectonismo deformador da Formação Itaqueri na porção centro-leste do Estado de São Paulo. São Paulo: Revista do Instituto Geológico, 18(1/2):41-48.

SALVADOR, E.D. \& RICCOMINI, C. 1995. Neotectônica da Região do Alto Estrutural de Queluz (SP-RJ, Brasil). Revista Brasileira de Geociências, 25: 151-164.

SOARES, P.C.; BARCELLOS, P.E.; CSORDAS, S.M. 1982. Lineamentos em imagens de Landsat e radar e suas implicações no conhecimento tectônico da Bacia do Paraná. In: INPE, SIMPÓSIODE SENSORIAMENTOREMOTO, 2, Brasília, Anais, 1:143-156.
TARDY, Y. 1993. Pétrologie des latérites et des sols tropicaux. Masson et Cie. Editeurs, Paris, 256 p.

UNESP. 1986. Mapa geológico da quadrícula de Jundiaí. UNESP/PRÓ-MINÉRIO, São Paulo.

VASCONCELLOS, A.C.B. 1988. O Grupo Andrelândia na região a norte de Ouro Fino, MG. Instituto de Geociências, Universidade de São Paulo, São Paulo, Dissertação de Mestrado, 199p.

VIEIRA, A.J. 1973. Geologia do centro, nordeste e centro-sul de São Paulo. In: SBG, CONGRESSOBRASILEIRO DE GEOLOGIA, 27, Aracaju, Anais, 3:259-277.

VLACH, S.R.F.1993. Geologia e petrologia dos granitóides de Morungaba, SP. Instituto de Geociências, Universidade de São Paulo, São Paulo, Tese de Doutoramento, 414 pp.

ZALÁN, P.V.; WOLF, S.; CONCEIÇÃO, J.C.J.; ASTOLFI, M.A.M.; VIEIRA, I.S.; APPI, V.T.; ZANOTTO, O.A.; MARQUES, A. 1991. Tectonics and sedimentation of the Paraná Basin. In: H. Ulbrich \& A.C. Rocha Campos (eds.), GONDWANA SEVEN, Proceedings, São Paulo, p. 83-117.

Endereço dos autores:

Amélia João Fernandes - Instituto Geológico, Secretaria do Meio Ambiente, Av. Miguel Stefano 3900, CEP 04301-903, São Paulo, SP. E-mail: ameliajf@igeologico.sp.gov.br

Claudio Limeira Mello - Instituto de Geociências, Universidade Federal do Rio de Janeiro, Prédio CCMN, Cidade Universitária, Ilha do Fundão, Rio de Janeiro, RJ. CEP 21941-590. E-mail: limeira@geologia.ufrj.br 